critical if a favourable outcome is to be achieved. ${ }^{7}$ Antifungal treatment is problematic as no studies have addressed this subgroup of patients specifically. Certainly the milder variants of aspergillus tracheobronchitis have been successfully treated with oral itraconazole, ${ }^{56}$ but those with pseudomembranous disease are more advanced and are thus a much greater therapeutic challenge.

In consideration of the above we recommend that, in the clinical setting of unremitting fever despite broad spectrum antibiotics in an immunocompromised patient, the presence of wheeze, particularly in the absence of a history of chronic airways disease, should raise the possibility of endobronchial disease and prompt early bronchoscopic examination.

1 Young RC, Bennett JE, Vogel CL, Carbone PP, DeVita VT. Aspergillosis. The spectrum of the disease of 98 patients. Medicine (Baltimore) 1970;49:147-73.

2 Meyer RD, Young LS, Armstrong D, Yu B. Aspergillosis complicating neoplastic disease. Am $\mathcal{f}$ Med 1973;54: $6-15$.

3 Clarke A, Skelton J, Fraser RS. Fungal tracheobronchitis. Report of 9 cases and review of the literature. Medicine (Baltimore) 1991;70:1-14.

4 Fisher BD, Armstrong D, Yu B, Gold JWM. Invasive aspergillosis. Progress in early diagnosis and treatment. Am f Med 1981;71:571-7.

5 Kramer MR, Denning DW, Marshall SE, Ross DJ, Berry $\mathrm{G}$, Lewiston NJ, et al. Ulcerative tracheobronchitis after lung transplantation. Am Rev Respir Dis 1991;144: $552-6$.

6 Denning DW, Follansbee SE, Scolaro M, Norris S, Edelstein H, Stevens DA. Pulmonary aspergillosis in the acquired immunodeficiency syndrome. $N$ Engl $f \mathrm{Med}$ 1991;324:654-62.

7 Angelucci E, Ugolini M, Lucarelli G, Raspugli $M$, Baronciani D, Galimberti $\mathrm{M}$, et al. Endobronchial aspergillosis in marrow transplant patients. Bone Marrow Transplant 1991;8:328-9.

8 Hall J, Heimann P, Costas C. Airway obstruction caused by aspergillus tracheobronchitis in an immunocompromised patient. Crit Care Med 1990;18:575-6.

9 Hofeler H, Popescu O, Kath R, Hoffken K, Schmidt CG. Invasive bronchopulmonary aspergillosis leading to rapidly progressive respiratory failure in a patient with severe aplastic anaemia. Klin Wochenschr 1987;65: s30-2.

10 Pervez NK, Kleinerman J, Kattan M, Freed JA, Harris $\mathrm{MB}$, Rosen MJ, et al. Pseudomembranous necrotizing bronchial aspergillosis. Am Rev Respir Dis 1985;131: 961-3.

\section{Pulmonary nodules due to reactive systemic amyloidosis (AA) in Crohn's disease}

\author{
T W Beer, C W Edwards
}

\begin{abstract}
Multiple nodules of AA (reactive systemic) amyloid were identified at necropsy in the lungs of a patient with Crohn's disease. No other organs were involved. Nodular pulmonary amyloidosis is usually caused by deposition of AL (primary) amyloid.
\end{abstract}

(Thorax 1993;48:1287-1288)

Department of

Histopathology,

Pathology Laboratory,

Warwick CV34 5BJ

T W Beer

\section{Department of}

Histopathology, East

Birmingham Hospital,

Birmingham, B19 5ST

C W Edwards

Reprint requests to:

Dr T W Beer, Department

of Histopathology, South

Block Level E,

Southampton General

Hospital, Tremona Road,

Southampton S09 4XY

Received 16 November 1992

Returned to authors

19 January 1993

Revised version received

1 February 1993

Accepted 23 February 1993

\section{Case report}

A 75 year old woman presented with a two month history of diarrhoea and two stone weight loss. She had features of congestive cardiac failure and her chest radiographs showed diffuse basal shadowing only, obscuring any further disease. Three days after hos- pital admission the patient sustained a fatal cardiac arrest.

There was no history of drug ingestion and no significant past medical history, but she was a heavy smoker.

At necropsy no lesions of the tongue or skin were seen. Recent myocardial infarction was confirmed and each pleural cavity contained $500 \mathrm{ml}$ of clear effusion fluid. The lungs were oedematous, together weighing $1480 \mathrm{~g}$. Throughout both lungs, but predominantly in the bases, there were 12 well circumscribed nodules of firm, brown, waxy material up to $3 \mathrm{~cm}$ in diameter. There was a terminal ileitis and patchy colitis with a cobblestone mucosal pattern and areas of fibrous stenosis.

Histological examination showed that the pulmonary nodules were composed of amyloid with scattered foci of calcification and ossification. They stained pink with Congo red eliciting apple-green dichroism in polarised light (figure). Staining was abolished by pretreatment of the sections with potassium permanganate. Immunohistochemical examination with the avidin-biotin complex method showed positive staining for amyloid A component (Dako, UK). The ileum and colon showed features of active Crohn's disease.

Congo red staining of all major organs (including myocardium, kidney, bladder, liver, spleen, small and large intestine, adrenal, thyroid, and pancreas) revealed no evidence of amyloid deposition.

\section{Discussion}

Nodular pulmonary amyloidosis is an uncommon but recognised manifestation of amyloid 


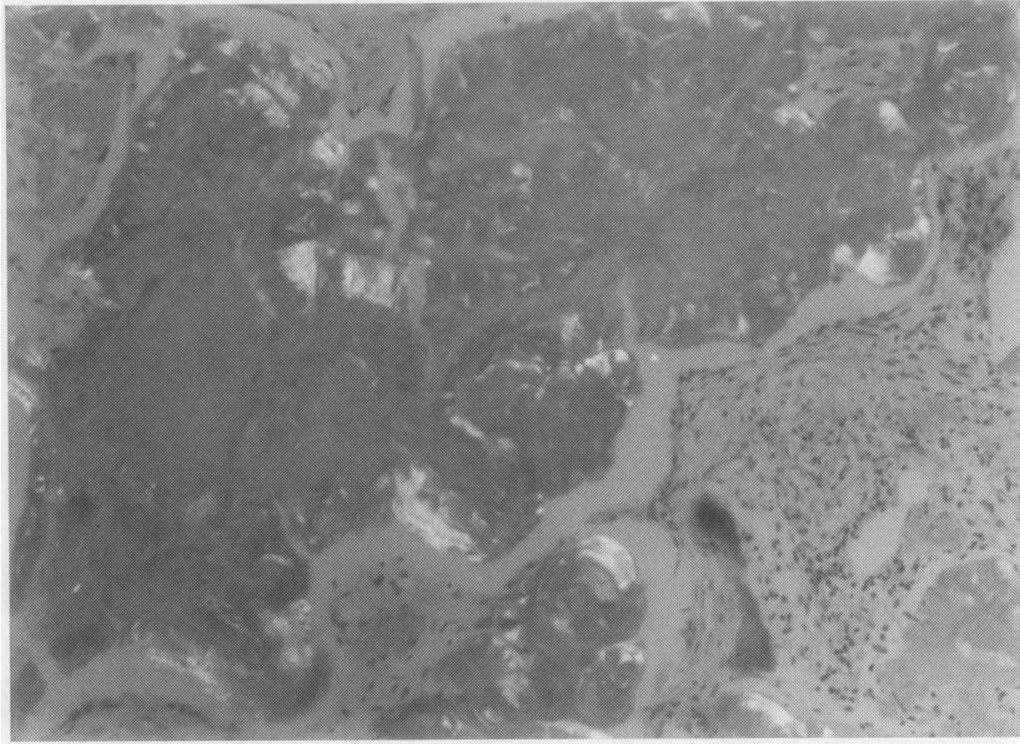

One of the nodular deposits of amyloid showing dichroism in polarised light. Stain: Congo red. Original magnification $\times 100$, reduced to $75 \%$ in origination.

disease. ${ }^{1-4}$ Most deposits are asymptomatic, some presenting as nodular shadows on chest radiography. ${ }^{5}$ In most cases the amyloid is of AL type and confined to the lungs. ${ }^{146-8}$ In this report nodular pulmonary deposits of AA (reactive systemic) amyloid were seen in a patient with active Crohn's disease. The amyloid was restricted to the pulmonary nodules with none in organs customarily involved in reactive sytemic or senile amyloidosis.
Crohn's disease is infrequently complicated by amyloidosis 9 but usually follows the pattern of reactive systemic amyloidosis. ${ }^{10}$ In the absence of an alternative explanation it is suggested that the unusual amyloid deposits in this patient occurred as a consequence of Crohn's disease.

We are indebted to Dr A Savage for her helpful advice and for undertaking the immunostaining. We are also grateful to Dr E J Vella, to Mrs G Oliver for typing the manuscript, and to $\mathrm{Dr} \mathrm{H}$ Desai for permission to report the case.

1 Hui AN, Koss MN, Hochholzer L, Wehunt WD Amyloidosis presenting in the lower respiratory tract. Arch Pathol Lab Med 1986;110:212-8.

2 Firestone FN, Joison J. Amyloidosis: a cause of primary tumours of the lung. $\mathcal{F}$ Thorac Cardiovasc Surg 1966;51:292-9.

3 Saab SB, Burk J, Hopeman A. Primary pulmonary amyloidosis. Report of two cases. $\mathcal{F}$ Thorac Cardiovasc Surg 1974;67:301-7.

4 Laden SA, Cohen ML, Harley RA. Nodular pulmonary amyloidosis with extrapulmonary involvement. Hum Pathol 1984;15:594-7.

5 Cotton RE, Jackson JW. Localized amyloid "tumours" of the lung simulating malignant neoplasms. Thorax 1964;19:97-103.

6 Smith RRL, Hutchins GM, Moore GW, Humphrey RL Type and distribution of pulmonary parenchymal and vascular amyloid. Am ₹ Med 1979;66:96-104

7 Tamura K, Nakajima N, Makino S, Maruyama R, Kohno T, Koga Y. Primary pulmonary amyloidosis with multiple nodules. Eur 7 Radiol 1988;8:128-30.

8 Page DL, Isersky C, Harada M, Glenner GG. Immunoglobulin origin of localized nodular pulmonary amyloidosis. Res Exp Med 1972;159:75-86.

9 Shorven PJ. Amyloidosis and inflammatory bowel disease. Am f Dig Dis 1977;22:209-13.

10 Werther J Schapira A, Rubinstein O, Janowitz HD. Amyloid in regional enteritis. A report of 5 cases. $A m \mathcal{F}$ Med 1960;29:416-23.

\section{BOOK NOTICE}

Intensive Respiratory Care. 2nd edition. J M Luce, D J Pierson and M L Tyler. (Pp358; £16.95). Philadelphia: Saunders, 1993. 0721642705.

This is the second edition of a small handbook intended for medical and nursing staff, both at student and practising levels. It is stated in the preface that the subject matter is tied by the common thread of applied respiratory physiology, and indeed this book does provide a practical and didactic guide to care of the respiratory patient with a strong emphasis on their physiological defects and their management. This is a welcome deviation from the more common diagnosis based approach to respiratory disease and provides an introduction, as the book's title suggests, to the practices required in respiratory intensive care. Although there is much useful information within this manual, it fails to be consistent in its assumption of basic knowledge; in some places so little knowledge is assumed that the descriptions become extremely laboured-for instance, the description of partial pressures in the opening chapter-whereas in other parts limited information is given and presumably the reader is expected to have the knowledge. Furthermore, the balance of information seems to be inadequate in some placesfor instance, in the third chapter on water and solute balance there is very limited description of capillary water movement and an extremely detailed description of cell water movement. Similarly, the chapter on diagnosis of respiratory disease provides an excellent description of the physiology behind respiratory symptoms and signs, but gives very little detail to the physiology behind respiratory function tests radiography.

The book opens with chapters on anatomy and physiology, the physiology of water and solute balance, acid base physiology, and a physiological approach to respiratory diseases tying together the basics very well. The chapter on respiratory failure again covers the physiological aspects very well, but the reader is left with very little information on how to manage respiratory failure. The management of the airway is covered in two excellent chapters dealing with methods of keeping the airway open and methods of improving airway clearance. Therapeutics are discussed with a single chapter on drugs, although drug interactions are poorly covered. The use of paralysing agents in intensive care is covered, but sedatives are not mentioned. Although most drugs are covered in this single chapter, aerosol therapy is given a very full and detailed chapter of its own. Mechanical ventilation is discussed in a chapter which opens with ways of avoiding mechanical ventilation and gives a limited description of the various modes of ventilation. Useful in a respiratory manual is a chapter dealing with the disposition of oxygen once it has crossed the lungs; related to this there is an excellent chapter on the $O$ "whys and wherefores" of monitoring. There are some glaring omissions. Infection control is covered in a full chapter dealing with transmission of HIV disease but $\cong$ the common respiratory problems of HIV disease are not mentioned. The reader who expects this book to be a respiratory intensive care manual will be disappointed. Those who expect what the title literally promises should be reasonably satisfied. This point is emphasised with an excellent chapter on home respiratory care, covering home oxygen therapy and home ventilation with useful information on patient selection and support.

In conclusion, this book has a place on the bookshelves of medical students and junior doctors. It is an additional source of information that is often not well covered in standard respiratory textbooks, but it certainly cannot replace these.-ARW 